\title{
Characterization and assessment of biosurfactant producing indigenous hydrocarbonoclastic bacteria: potential application in bioremediation
}

\author{
Pranjal Bharali ${ }^{1}$, Salam Pradeep Singh ${ }^{2,3, 凶}$, Yasir Bashir ${ }^{3}$, Nipu Dutta $^{4}$, \\ Bolin Kumar Konwar ${ }^{3}$ and Chingakham Brajakishor Singh ${ }^{2}$ \\ ${ }^{1}$ Department of Environmental Science, Nagaland University, HQ: Lumami, Zunheboto, 798627, Nagaland, India \\ ${ }^{2}$ Institute of Bio-resources and Sustainable Development, Takyelpat, Imphal, 795001, Manipur, India \\ ${ }^{3}$ Department of Molecular Biology and Biotechnology, Tezpur University, Tezpur, 784028, Assam, India \\ ${ }^{4}$ Department of Chemical Sciences, Tezpur University, Napaam, Tezpur, 784028, Assam, India
}

\section{Article info}

\section{Article history:}

Received: $13^{\text {th }}$ March 2018

Accepted: $20^{\text {th }}$ August 2018

\section{Keywords:}

Bacillus circulans

Biodegradation

Bioremediation

Biosurfactant

Hydrocarbonoclastic

Pseudomonas aeruginosa

\begin{abstract}
Petroleum and hydrocarbons contamination can be remediated by physical, chemical or biological methods. Among these, in situ bioremediation is considered to be environmentally friendly because it restores the soil structure, requires less energy input and involves the notable removal after degradation of biosurfactant. The present study involves the characterization and assessment of biosurfactant producing indigenous hydrocarbonoclastic bacteria and their potential application in bioremediation processes. Three bacterial strains were isolated from various crude oil contaminated environments and characterized using standard identification techniques. The results clearly demonstrate the capability of utilizing hydrocarbon and biosurfactant produced by the bacterial strains. 16S rDNA sequencing followed by BLAST analysis revealed their similarity to Pseudomonas aeruginosa. The physico-chemical characterization of the biosurfactants revealed significant surface properties with stability at extreme temperature conditions (up to $121{ }^{\circ} \mathrm{C}$ ), $\mathrm{pH}(5-8)$ and salinity (up to $4 \%$ ). Further, the mass spectrometry confirmed predominance of di-rhamnolipids in biosurfactant mixtures. The biosurfactants were found to be efficient in the removal of crude oil from the contaminated sand suggesting its applicability in bioremediation technology. Further, improved discharge of crude oil at elevated temperatures also confirms their thermo-stability which, could be exploited in microbial enhanced oil recovery processes. Thus, the applications of biosurfactants produced by the indigenous hydrocarbonoclastic strains appeared to be advantageous for bioremediation of petroleum-contaminated environments.
\end{abstract}

(C) University of SS. Cyril and Methodius in Trnava

\section{Introduction}

Soil which is accidentally contaminated with petroleum hydrocarbons can be remediated by physical, chemical or biological methods. Among all, in situ bioremediation is considered to be environmentally friendly because it restores the soil structure, requires less energy input, and involves the notable removal after degradation of biosurfactant. Although most of the hydrocarbons are biodegradable, the rate of biodegradation in the environment is limited due to their hydrophobicity or less accessibility to microbes and low aqueous solubility (Radzuan et al. 2017). One of the approaches to enhance biodegradation of crude oil contamination is the 
use of biosurfactants which increase the solubility of hydrophobic substrates/oils in an aqueous medium to enhance their bioavailability leading to higher oil degradation (Zhang et al. 2017). The treatment of crude oil contaminated soil and environments through the indigenous biosurfactant producing bacteria having the capacity to degrade the petroleum hydrocarbons seems to be advantageous (Kuppusamy et al. 2017).

Most of the bacteria such as Pseudomonas putida, $P$. aeruginosa, $P$. saccharophila, Flavobacterium sp., Burkholderia cepacia, Rhodococcus sp., and Mycobacterium sp. etc. dwelling in the crude oil contaminated environment have the capacity to utilize the components of crude oil as the source of carbon and energy for their growth. They tend to secrete biosurfactants which in turn help in the degradation of crude oil components (Radzuan et al. 2017). Moreover, the production of biosurfactant at the site of treatment with the producer bacteria doesn't require rigorous testing like that of the chemical surfactants because of their environment-compatible nature (Pristas et al. 2015; Rahman et al. 2016). Therefore, the application of biosurfactants in bioremediation might be more acceptable from the social point of view. Thus there is a need for increased production of biosurfactants and their characterization.

The present study focuses on the application of indigenous bacterial strains for bioremediation processes as there is no need for them to get established in a new environment and they can coexist with the already inhabiting microbiota in the soil. Their population density can be enhanced by supporting their growth factors. Moreover, these bacteria don't need to add biosurfactant manually being able to produce biosurfactants by utilizing the contaminating petroleum hydrocarbons. The study involves the isolation, characterization, and application of the biosurfactants along with their producer strains in bioremediation processes.

\section{Experimental}

\section{Isolation of biosurfactant producing hydrocarbonoclastic bacteria}

The environmental samples includes crude oil- contaminated soils of oil fields, petroleum sludge and waste residual crude oil from the dump sites of oil and natural gas corporation (ONGC), Jorhat, Assam; petroleum sludge from the oil fields of ONGC, Sibsagar, Assam; contaminated soil samples from the different oil depots of Tezpur, Assam. The bacterial strains were isolated from the above samples using enrichment culture technique on mineral salt medium (MSM) (Bharali and Konwar 2011). Morphologically different bacterial colonies thus obtained were further purified on MSM agar plates with or without $0.1 \%(v / v)$ $n$-hexadecane to eliminate autotrophs and agarutilizing bacteria. The procedure was repeated and isolates showing pronounced growth on $n$-hexadecane were selected and preserved for further characterization (Parthipan et al. 2017).

Screening for biosurfactant production by the selected strains was done using de novo ring method, qualitative drop-collapse test and oil displacement test (Bodour and Maier 1998). Detection and quantification of biosurfactant produced by the selected strains were determined by three independent tests viz. cetyl triammonium bromide (CTAB) agar test (Siegmund and Wagner 1991), blood agar test (Johnson and BoeseMarrazzo 1980) and orcinol assay (Chandrasekaran and BeMiller 1980).

\section{Molecular and morphological characterization of selected isolates}

The 16S rRNA gene sequencing of the selected bacterial isolates was performed and the similarity search for the sequences thus obtained was done using NCBI BLAST. The sequences showing maximum similarity from the BLAST search were taken for phylogenetic analysis using MEGA 5.1 (Kumar et al. 1994). On the basis of partial 16S rRNA gene sequencing as well as with the use of NCBI BLAST, these three bacterial isolates $\mathrm{OBP} 2, \mathrm{OBP} 3$ and $\mathrm{OBP} 4$ were found to be closely related to Pseudomonas aeruginosa with $99 \%$ similarity in all the strains. The partial 16S rRNA gene sequences of the bacterial strains OBP2, OBP3 and OBP4 were deposited in the GenBank database under the accession numbers 1568199, 1568206 and 156820, respectively. Phylogenetic tree was constructed using the 
Neighbour-Joining method and all the three bacterial isolates were identified as Pseudomonas aeruginosa using MEGA 5.1 (Kumar et al. 1994). On the basis of colony morphology, physiology and biochemical characterization details three selected bacterial isolates were found to be under the genus Pseudomonas.

\section{Isolation of biosurfactants}

Each culture broth was centrifuged at $12,000 \mathrm{rpm}$ for 20 min at $4{ }^{\circ} \mathrm{C}$. $6 \mathrm{~N} \mathrm{HCl}$ was used to adjust the $\mathrm{pH}$ of the culture supernatant at 2.0 and kept overnight at $4{ }^{\circ} \mathrm{C}$. The precipitate thus obtained was extracted thrice with an equal volume of ethyl acetate. The upper organic phase was collected and dried. The brownish oily residue left behind was then dissolved in $3.0 \mathrm{~mL}$ of $0.1 \mathrm{M}$ sodium phosphate buffer ( $\mathrm{pH}$ 7.2) (Mulligan and Gibbs 2004).

\section{Chemical characterization of biosurfactants}

The thin layer chromatography technique (TLC) was used to detect the carbohydrate and lipid moieties using a mobile phase system consisting of chloroform: methanol: water (65:15:2). Anthrone, ninhydrin and iodine fumes were used as developing agents for carbohydrate, amino acids and lipid, respectively (Silva et al. 2017). The IR spectrum of the isolated biosurfactant was recorded in potassium bromide pellet using an FTIR spectrophotometer (Nicolos Impact 410). The liquid chromatographic and mass spectroscopic (LC-MS) study of the isolated biosurfactant samples was carried out using the standard protocol (Haba et al. 2003) on a Perkin Elmer system. The carrier gas was helium, maintained at the flow rate of 1.5 L. $\mathrm{min}^{-1}$.

\section{Physical characterization}

\section{Estimation of surface activity}

The surface tension of the cell-free culture supernatants was measured using a digitalized tensiometer (Krüss Tensiometer K9 ET/25) at $25 \pm 1{ }^{\circ} \mathrm{C}$ (Bodour and Maier 1998). The interfacial tension was measured against diesel. Each experiment was repeated thrice. Critical micelle concentration of the isolated biosurfactant samples was determined by measuring the surface tension of the aqueous biosurfactant at different concentrations up to the constant value of surface tension. Further, the surface tension of aqueous biosurfactant samples was determined at their critical micelle dilutions (CMD) of 10and 100-times, i.e., $\mathrm{CMD}^{-1}$ and $\mathrm{CMD}^{-2}$, respectively. Each measurement was repeated in triplicates.

\section{Emulsification activity $\left(E_{24}\right)$ and Foaming index $\left(F_{24}\right)$}

The emulsification index $\left(E_{24}\right)$ (in \%) was measured using the standard method described by Kumar et al. (2015). Different hydrocarbons were used for testing the emulsification efficiency. $20 \mathrm{~mL}$ of each biosurfactant solution $\left(1 \mathrm{~g} . \mathrm{L}^{-1}\right)$ was transferred to a glass measuring cylinder and compressed $\mathrm{N}_{2}$ gas was passed through the solution at a flow rate of $0.5 \mathrm{~L} \cdot \mathrm{min}^{-1}$ for $2 \mathrm{~min}$ (Zaman 2010; García-Reyes et al. 2017). The foaming index $\left(F_{24}\right)$ (in \%) of the biosurfactant samples was calculated after $24 \mathrm{~h}$.

\section{Stability in surface properties}

To determine the stability in relation to the temperature, $10 \mathrm{~mL}$ of each cell-free culture supernatant was exposed to various temperature viz. $4{ }^{\circ} \mathrm{C}, 25{ }^{\circ} \mathrm{C}, 37^{\circ} \mathrm{C}, 50{ }^{\circ} \mathrm{C}, 75^{\circ} \mathrm{C}$, and $100^{\circ} \mathrm{C}$ for $60 \mathrm{~min}$ and $121^{\circ} \mathrm{C}$ for $30 \mathrm{~min}$ (i.e. autoclaving) separately. After the treatment, the cell-free culture supernatants were kept at laboratory temperature (LT) $\left(20 \pm 1{ }^{\circ} \mathrm{C}\right)$ for $20 \mathrm{~min}$ after which the surface tension of each culture supernatant was measured at normal concentration (i.e. without dilution), at $\mathrm{CMD}^{-1}$ and $\mathrm{CMD}^{-2}$ and the emulsification index against diesel was measured. To study the $\mathrm{pH}$, the stability of the biosurfactant and the $\mathrm{pH}$ of the culture supernatant were adjusted to different $\mathrm{pH}$ values $(2-11)$. The surface tension of each treated culture supernatant was also measured at normal concentration, and emulsification index against diesel was measured. Similarly, the effect of $\mathrm{NaCl}$ concentrations $(1-5 \%)$ on the surface tension 
Table 1. Influence of $\mathrm{pH}$ on the surface activity of biosurfactant produced by $P$. aeruginosa strains in $2 \% n$-hexadecane supplemented medium at normal and critical micelle dilutions $\left(\mathrm{CMD}^{-1}\right.$ and $\left.\mathrm{CMD}^{-2}\right)$.

\begin{tabular}{lllll}
\hline \multirow{2}{*}{ Bacterial strains } & \multicolumn{3}{c}{ Surface tension [mN/m] } \\
\cline { 2 - 5 } & $\mathbf{p H}$ & Cell-free culture supernatant & CMD $^{-1}$ & CMD $^{-2}$ \\
\hline P. aeruginosa $O B P 2$ & 2 & $41.5 \pm 0.58$ & $48.9 \pm 0.78$ & $63.7 \pm 0.31$ \\
& 5 & $37.8 \pm 0.35$ & $41.0 \pm 0.23$ & $58.3 \pm 0.46$ \\
& 7 & $37.6 \pm 0.11$ & $40.7 \pm 0.83$ & $57.6 \pm 0.29$ \\
& 8 & $38.1 \pm 0.34$ & $41.5 \pm 0.69$ & $58.8 \pm 0.36$ \\
& 11 & $39.7 \pm 0.53$ & $43.2 \pm 0.45$ & $61.0 \pm 0.53$ \\
& 2 & $40.4 \pm 0.36$ & $46.3 \pm 0.93$ & $63.5 \pm 0.29$ \\
. aeruginosa OBP3 & 5 & $35.7 \pm 0.31$ & $38.7 \pm 0.67$ & $56.8 \pm 0.49$ \\
& 7 & $35.4 \pm 0.19$ & $38.2 \pm 0.30$ & $55.6 \pm 1.00$ \\
& 8 & $36.5 \pm 0.83$ & $39.5 \pm 0.47$ & $57.4 \pm 0.19$ \\
& 11 & $38.7 \pm 0.62$ & $42.5 \pm 0.61$ & $60.8 \pm 0.38$ \\
& 2 & $38.5 \pm 0.43$ & $43.3 \pm 0.60$ & $57.1 \pm 0.51$ \\
& 5 & $33.7 \pm 0.76$ & $39.8 \pm 0.71$ & $50.3 \pm 0.94$ \\
& 7 & $33.1 \pm 0.93$ & $39.5 \pm 0.35$ & $48.7 \pm 0.54$ \\
& 8 & $33.6 \pm 0.51$ & $39.7 \pm 0.29$ & $51.4 \pm 0.66$ \\
& 11 & $35.8 \pm 0.23$ & $41.4 \pm 0.72$ & $54.9 \pm 0.39$ \\
\hline
\end{tabular}

Values represent mean of three replicates.

of the culture supernatant at normal concentration was studied and emulsification activity was determined. Synthetic surfactant sodium dodecyl sulphate (SDS) was used as a standard and the assays were carried out in triplicates.

\section{Possible industrial application of biosurfactant- sand pack column experiment}

The sand pack column experiment was carried out as described by Suthar et al. (2008). A vertical glass column with a dimension of $25 \mathrm{~cm} \times 3 \mathrm{~cm}$ (internal diameter) was packed with $150 \mathrm{~g}$ of acidwashed sand. The column was initially saturated with brine (5 \% NaCl solution), followed by flooding with crude oil supplied by Oil and Natural Gas Corporation Limited (ONGCL), Assam, India. The column was further flooded with brine until no further oil appeared in the effluent. Finally, the cell-free culture supernatant of stationary phase of growth was pumped into the column. The oil released from the column after exposure to various temperatures $(20,50,70$ and $90{ }^{\circ} \mathrm{C}$ ) was measured. Each experiment was repeated in triplicates.

\section{Soil washing experiment}

Crude oil contaminated sand samples, each weighing $20 \mathrm{~g}$, were transferred to $250 \mathrm{~mL}$ Erlenmeyer flasks containing $100 \mathrm{~mL}$ aqueous biosurfactant solution of various concentrations (0.001, 0.005, 0.007, 0.01 and $0.1 \% ; w / v)$ and kept at $150 \mathrm{rpm}$ for $24 \mathrm{~h}$ at laboratory temperature (LT) $\left(20 \pm 1{ }^{\circ} \mathrm{C}\right)$. The contaminated sand samples were separated, dried and washed twice with dichloromethane. The solvent part was removed and the residual oil was determined gravimetrically (Chen et al. 2017).

\section{Results and Discussion}

\section{Isolation and characterization of potential}

biosurfactant producing hydrocarbonoclastic

bacteria

A total of 52 cultivable isolates were obtained based on colony morphology analysis. On further experimentation, 3 isolates were found to be the potential users of hydrocarbons and producers of biosurfactants as determined by their biomass yield and surface properties. Thus, causing a reduction in the surface tension of the culture medium from $37.6 \pm 0.51 \mathrm{mN} . \mathrm{m}^{-1}$ to a minimum of $33.2 \pm 0.79 \mathrm{mN} . \mathrm{m}^{-1}$, while growing on $n$-hexadecane. The bacterial isolates were designated as OBP2, OBP3 and OBP4. 

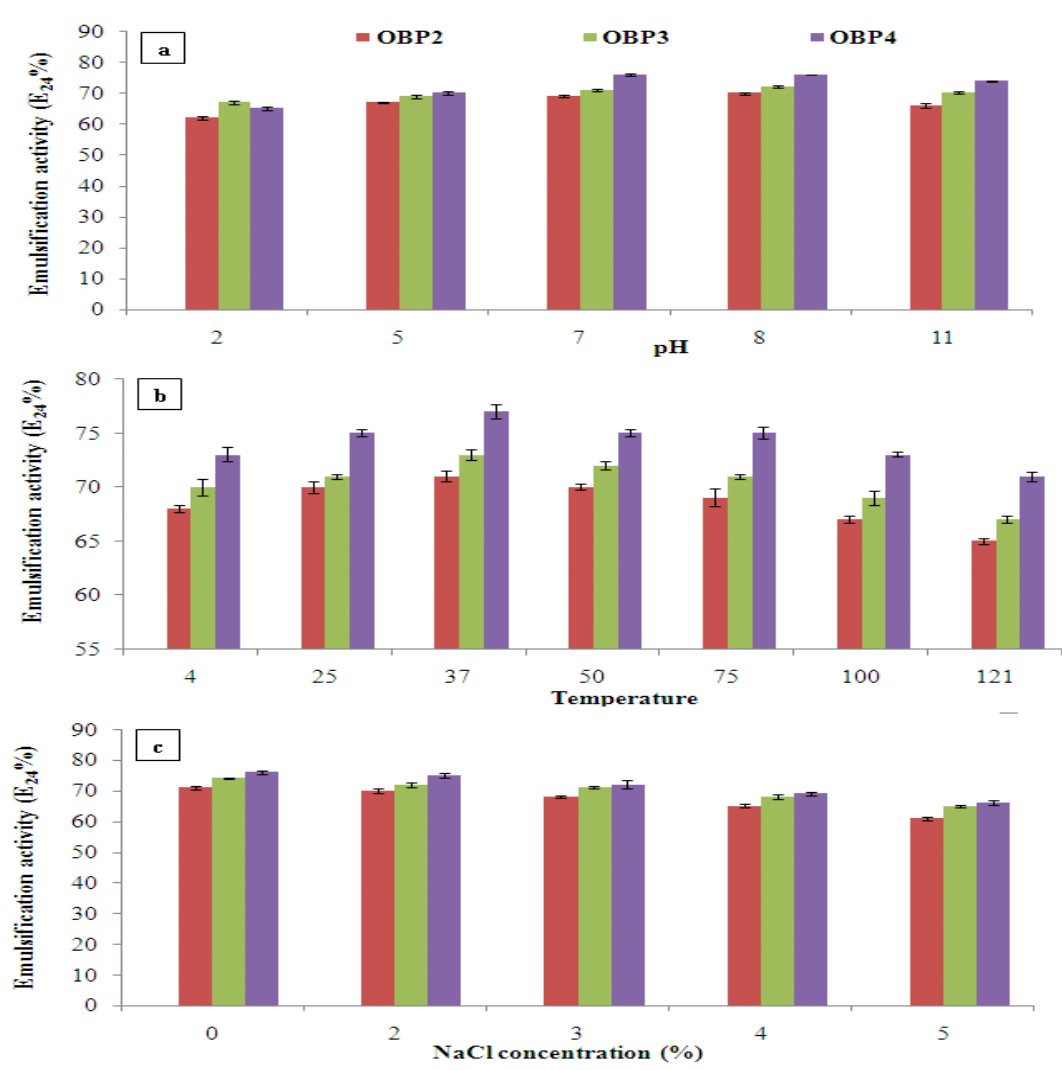

Fig. 1. Effect of (a) $\mathrm{pH},(\mathbf{b})$ temperature, and (c) salinity $(\mathrm{NaCl})$ on the emulsifying properties $\left(E_{24}\right)$ of culture supernatants of $P$. aeruginosa strains against diesel. Results represent the mean of three independent experiments \pm standard deviation.

Among the screening techniques, all the selected bacterial strains showed positive results in hemolysis assay, CTAB agar assay, and glycolipid quantification test. All three bacterial strains exhibited a distinct zone of hemolysis in blood-agar plates containing $2 \%$ $(v / v)$ goat blood. Hemolysis assay is widely used for the screening of biosurfactant producing bacteria and could be used for the quantification of glycolipid-type biosurfactant produced by bacteria (Banat 1993; Yonebayashi et al. 2000). All the three bacterial strains could grow on CTAB agar plates forming blue halos around the colonies. The CTAB agar test is another technique used for the detection of glycolipid-type biosurfactant production by the bacterial colonies in the culture plate directly (Irorere et al. 2017). Aparna et al. (2012) reported screening of rhamnolipid producing thermophilic hydrocarbon-degrading Pseudomonas aeruginosa strains by CTAB agar method from the soil contaminated with petroleum products. The concentration of biosurfactant present in the culture medium of the bacterial strains was determined using the orcinol assay and the production was $8.8 \pm 0.6,9.2 \pm 1.1$ and $9.8 \pm 0.5$ for OBP2, OBP3 and OBP4, respectively.

The genus Pseudomonas is reported to be the most versatile group due to its inherent ability to utilize a diverse range of substrates as the carbon source, particularly those found in petroleum (Saikia et al. 2012). Bordoloi and Konwar (2007) reported the predominance of the bacterial genus Pseudomonas in the North Eastern region of India especially in the petroleum contaminated environments of Assam and Assam-Arkan Basin, ONGC.

\section{Physical characterization of biosurfactants}

The surface tension of the culture medium of bacterial strains OBP2, OBP3 and OBP4 were drastically reduced by the bacterial strains from 68.5 to $37.6 \pm 0.51,35.5 \pm 0.38,33.2 \pm 0.79 \mathrm{mN} . \mathrm{m}^{-1}$, respectively. Reductions in the IFT of diesel containing culture supernatant of bacterial strains OBP2, OBP3 and OBP4 as compared to the control culture medium without any bacteria are $3.4 \pm 0.48$, $2.8 \pm 0.93, \quad 2.2 \pm 0.28 \quad \mathrm{mN} . \mathrm{m}^{-1}$ respectively. The biosurfactant produced by the bacterial strains was able to reduce the surface tension of the culture medium significantly. Further, they were effectively reducing the IFT between diesel and 
Table 2. Influence of temperature on the surface activity of biosurfactant produced by $P$. aeruginosa strains in $2 \%$ $n$-hexadecane supplemented medium at normal and critical micelle dilutions $\left(\mathrm{CMD}^{-1}\right.$ and $\left.\mathrm{CMD}^{-2}\right)$.

\begin{tabular}{|c|c|c|c|c|}
\hline \multirow[b]{2}{*}{ Bacterial strains } & \multirow[b]{2}{*}{$\begin{array}{l}\text { Exposure to } 60 \mathrm{~min} \text { at } \\
\text { the temperature }\left[{ }^{\circ} \mathrm{C}\right]\end{array}$} & \multicolumn{3}{|c|}{ Surface tension $\left[\mathrm{mN} \cdot \mathrm{m}^{-1}\right]$} \\
\hline & & $\begin{array}{l}\text { Cell-free culture } \\
\text { supernatant }\end{array}$ & $\mathrm{CMD}^{-1}$ & $\mathrm{CMD}^{-2}$ \\
\hline \multirow[t]{7}{*}{ P. aeruginosa $\mathrm{OBP} 2$} & 4 & $38.3 \pm 0.41$ & $43.0 \pm 0.25$ & $58.1 \pm 0.29$ \\
\hline & 25 & $37.5 \pm 0.38$ & $40.3 \pm 0.48$ & $57.6 \pm 0.38$ \\
\hline & 37 & $37.6 \pm 0.28$ & $40.8 \pm 0.39$ & $57.5 \pm 0.65$ \\
\hline & 50 & $37.8 \pm 0.37$ & $41.1 \pm 0.52$ & $57.8 \pm 0.75$ \\
\hline & 75 & $38.0 \pm 0.51$ & $41.6 \pm 0.41$ & $58.2 \pm 0.28$ \\
\hline & 100 & $39.4 \pm 0.20$ & $43.9 \pm 0.40$ & $59.3 \pm 0.47$ \\
\hline & 121 (for $30 \mathrm{~min}$ ) & $39.2 \pm 0.51$ & $44.2 \pm 0.35$ & $59.1 \pm 0.76$ \\
\hline \multirow[t]{7}{*}{$P$. aeruginosa $\mathrm{OBP} 3$} & 4 & $36.8 \pm 0.39$ & $39.6 \pm 0.77$ & $56.8 \pm 0.87$ \\
\hline & 25 & $35.5 \pm 0.38$ & $38.4 \pm 0.93$ & $55.3 \pm 0.54$ \\
\hline & 37 & $35.3 \pm 0.40$ & $38.3 \pm 0.38$ & $55.5 \pm 0.39$ \\
\hline & 50 & $35.3 \pm 0.19$ & $38.7 \pm 0.84$ & $55.9 \pm 0.82$ \\
\hline & 75 & $35.9 \pm 0.36$ & $39.4 \pm 0.62$ & $56.4 \pm 0.39$ \\
\hline & 100 & $38.3 \pm 0.72$ & $41.5 \pm 0.65$ & $59.2 \pm 0.35$ \\
\hline & 121 (for $30 \mathrm{~min}$ ) & $38.2 \pm 0.10$ & $41.8 \pm 0.94$ & $59.6 \pm 0.62$ \\
\hline \multirow[t]{7}{*}{ P. aeruginosa $\mathrm{OBP} 4$} & 4 & $34.7 \pm 0.39$ & $40.6 \pm 0.54$ & $49.5 \pm 0.82$ \\
\hline & 25 & $33.2 \pm 0.91$ & $39.8 \pm 0.77$ & $48.7 \pm 0.22$ \\
\hline & 37 & $33.2 \pm 0.32$ & $39.7 \pm 0.83$ & $48.8 \pm 0.91$ \\
\hline & 50 & $33.5 \pm 0.17$ & $39.7 \pm 0.39$ & $49.2 \pm 0.30$ \\
\hline & 75 & $33.7 \pm 0.63$ & $40.2 \pm 0.98$ & $49.7 \pm 0.45$ \\
\hline & 100 & $34.0 \pm 0.72$ & $43.8 \pm 0.74$ & $51.4 \pm 0.76$ \\
\hline & 121 (for $30 \mathrm{~min}$ ) & $34.6 \pm 0.83$ & $44.1 \pm 0.59$ & $51.2 \pm 0.98$ \\
\hline
\end{tabular}

Data represent Mean values, $n=3$.

water. It is considered as an important factor in oil recovery because capillary number increases with the decrease in the interfacial tension (Hajibagheri et al. 2017). The CMC values were found to be in the range of $105 \pm 0.34,90 \pm 0.58,65 \pm 0.94 \mathrm{mg} . \mathrm{L}^{-1}$ respectively. The $\mathrm{CMC}$ values obtained in this investigation differed within the strains as well as the other reported strains of $P$. aeruginosa. Previously, a range of CMC values between $10-230 \mathrm{mg} . \mathrm{L}^{-1}$ was reported for the rhamnolipids isolated from the different microbial sources. Such variation in the CMC values might be due to the intrinsic variability of the rhamnolipids accumulated and the complexity of its composition, number and proportions of homologues. The presence of unsaturated bonds, branching and length of the aliphatic chain of the rhamnolipid collectively affect the CMC and surface tension values between the rhamnolipids produced. In most of the instances, reduction in the surface tension at $\mathrm{CMD}^{-1}$ was almost similar to that of normal, whereas the $\mathrm{CMD}^{-2}$ caused a slight increase in the surface tension of the system due to the higher dilution. However, the biosurfactant of the bacteria strains maintains significant extent of their surface property which indicates their possible application in MEOR technology.

Addition to the surface and interfacial tensions, stabilization of an oil-water emulsion is usually used as an indicator of surface activity. The bacterial strains showed a wide difference in the emulsification activity against the test hydrocarbons. The cell-free culture supernatant of the bacterial strains exhibited appreciable emulsification indices against tested hydrophobic substrates especially against diesel, $n$-hexadecane followed by $n$-octadecane and crude oil. Further, the preference for hydrophobic substrates and the behavior of emulsification activity $\left(\mathrm{E}_{24}\right)$ were quite different among these $P$. aeruginosa strains. This may be because most of the microbial surfactants are substrate specific causing 
solubilization or emulsification of hydrocarbons at different rates.
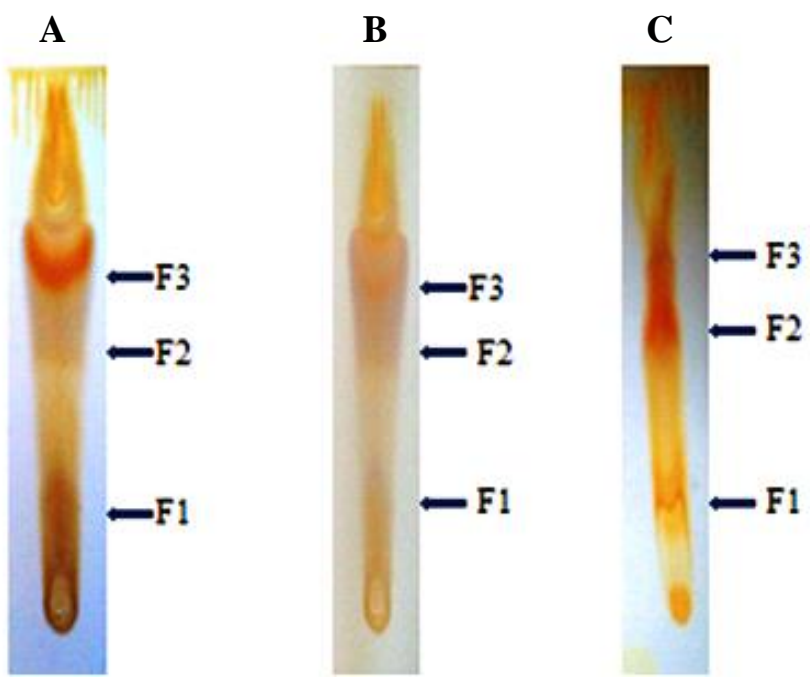

Fig. 2. Thin-layer chromatogram of biosurfactants produced by $P$. aeruginosa strains when cultivated in mineral salt medium supplemented with $n$-hexadecane. (A) $P$. aeruginosa OBP2, (B) $P$. aeruginosa OBP3, and (C) $P$. aeruginosa OBP4. F1-F3 represents fractions that exhibit positive results of surface activity.

The water-oil emulsions were found to be compact and remained stable at laboratory temperature (LT) $\left(20 \pm 1{ }^{\circ} \mathrm{C}\right)$ for more than one month suggesting a possible application of the biosurfactants in the bioremediation process for enhancing the availability of the recalcitrant hydrocarbons. Moreover, the ability of the biosurfactants to emulsify specifically the crude oil products might facilitate their microbial assimilation, which could be useful for the bioremediation of petroleum contaminated environments. Additionally, the ability of the biosurfactants to emulsify the vegetable oil also suggests their potential application in the pharmaceutical and cosmetic industries.

The cell-free culture supernatant of each bacterial strain produced stable foam with the foaming index $\left(F_{24}\right)$ in the range of $50.4-59.8 \%$. Foams produced by the cell-free culture supernatants of all three bacterial strains remained relatively stable up to $24 \mathrm{~h}$. Such characteristics of biosurfactants indicate their possible application in coal and mineral froth-flotation as a frothing and co-frothing agent (García-Reyes et al. 2017).

Biosurfactants produced by the bacterial strains at normal $\mathrm{CMD}^{-1}$ and $\mathrm{CMD}^{-2}$ concentrations were found to stable and showed optimum surface activity at pH $5-8$ (Table 1). The emulsification activity $\left(E_{24}\right)$ of the cell free culture supernatant of the bacterial strains against diesel was quite stable at $\mathrm{pH} 5-8$, though the optimum emulsifying activity was observed between $\mathrm{pH} 7-8$ (Fig. 1a). Considerable reduction in the stability as well as in the surface activity of biosurfactants was observed beyond $\mathrm{pH}$ 8. Such decrease in the surface activity might be due to the alteration of surfactant structures at the extreme $\mathrm{pH}$ conditions. Increase in $\mathrm{pH}$ from $5-8$ caused an increase in the negative charge on the polar head of the rhamnolipid molecule ( $p K_{a}$ 5.6) enhancing its solubility in water. However, below $\mathrm{pH} 5$,

Table 3. Influence of salinity on the surface activity of biosurfactant produced by $P$. aeruginosa strains in $2 \% n$-hexadecane supplemented medium at normal and critical micelle dilutions $\left(\mathrm{CMD}^{-1}\right.$ and $\left.\mathrm{CMD}^{-2}\right)$.

\begin{tabular}{|c|c|c|c|c|}
\hline \multirow[b]{2}{*}{ Bacterial strains } & \multirow[b]{2}{*}{$\begin{array}{c}\text { NaCl Concentration } \\
{[\%]}\end{array}$} & \multicolumn{3}{|c|}{ Surface tension [mN.m-1] } \\
\hline & & $\begin{array}{l}\text { Cell-free culture } \\
\text { supernatant }\end{array}$ & $\mathrm{CMD}^{-1}$ & $\mathrm{CMD}^{-2}$ \\
\hline \multirow[t]{5}{*}{ P. aeruginosa $\mathrm{OBP} 2$} & 0 & $37.4 \pm 0.43$ & $40.6 \pm 0.48$ & $57.7 \pm 0.26$ \\
\hline & 2 & $37.6 \pm 0.26$ & $40.9 \pm 0.71$ & $57.5 \pm 0.40$ \\
\hline & 3 & $37.9 \pm 0.39$ & $41.0 \pm 0.39$ & $57.8 \pm 0.40$ \\
\hline & 4 & $40.5 \pm 0.48$ & $43.7 \pm 0.51$ & $59.6 \pm 1.00$ \\
\hline & 5 & $46.6 \pm 0.65$ & $50.3 \pm 0.30$ & $61.9 \pm 0.49$ \\
\hline \multirow[t]{5}{*}{$P$. aeruginosa $\mathrm{OBP} 3$} & 0 & $35.4 \pm 0.28$ & $38.3 \pm 0.83$ & $55.5 \pm 0.72$ \\
\hline & 2 & $35.4 \pm 0.76$ & $38.5 \pm 0.62$ & $55.6 \pm 0.49$ \\
\hline & 3 & $35.7 \pm 0.39$ & $39.9 \pm 0.96$ & $55.6 \pm 0.49$ \\
\hline & 4 & $37.3 \pm 0.49$ & $41.0 \pm 0.70$ & $58.3 \pm 0.02$ \\
\hline & 5 & $43.1 \pm 0.65$ & $48.8 \pm 0.52$ & $59.8 \pm 0.39$ \\
\hline \multirow[t]{5}{*}{ P. aeruginosa $\mathrm{OBP} 4$} & 0 & $33.1 \pm 0.38$ & $39.7 \pm 0.30$ & $48.6 \pm 0.56$ \\
\hline & 2 & $33.3 \pm 0.29$ & $39.6 \pm 0.73$ & $48.6 \pm 0.75$ \\
\hline & 3 & $33.6 \pm 0.48$ & $39.7 \pm 0.40$ & $48.9 \pm 0.95$ \\
\hline & 4 & $36.0 \pm 0.20$ & $42.5 \pm 0.67$ & $50.4 \pm 0.34$ \\
\hline & 5 & $39.6 \pm 0.29$ & $48.2 \pm 0.93$ & $53.7 \pm 0.94$ \\
\hline
\end{tabular}


Table 4. Chemical composition of rhamnolipid mixture produced by $P$. aeruginosa strains as determined by mass spectroscopic analysis.

\begin{tabular}{|c|c|c|}
\hline Bacterial strains & Rhamnolipid congeners & Pseudomolecular ion $[\mathrm{m} / \mathrm{z}]$ \\
\hline P. aeruginosa $\mathrm{OBP} 2$ & $\begin{array}{c}\text { Rha-C } \mathrm{C}_{8: 2} \\
\text { Rha- } \mathrm{C}_{12: 2} \\
\text { Rha- } \mathrm{C}_{10}-\mathrm{C}_{10} \\
\text { Rha- } \mathrm{C}_{10}-\mathrm{C}_{12: 1} \\
\text { Rha-Rha- } \mathrm{C}_{10}-\mathrm{C}_{12} \\
\text { Rha-Rha- } \mathrm{C}_{12}-\mathrm{C}_{10} \\
\text { Rha-Rha- } \mathrm{C}_{10}-\mathrm{C}_{10} \\
\text { Rha-Rha- } \mathrm{C}_{10}-\mathrm{C}_{12: 1}\end{array}$ & $\begin{array}{l}302 \\
357 \\
501 \\
527 \\
531 \\
531 \\
648 \\
675\end{array}$ \\
\hline P. aeruginosa $\mathrm{OBP} 3$ & $\begin{array}{c}\text { Rha- } \mathrm{C}_{8: 2} \\
\text { Rha- } \mathrm{C}_{10} \\
\text { Rha- } \mathrm{C}_{8}-\mathrm{C}_{10} \\
\text { Rha-Rha- } \mathrm{C}_{10} \\
\text { Rha-C } \mathrm{C}_{10}-\mathrm{C}_{10} \\
\text { Rha- } \mathrm{C}_{10}-\mathrm{C}_{12: 1} \\
\text { Rha-Rha- } \mathrm{C}_{10}-\mathrm{C}_{12} \\
\text { Rha-Rha-C } 12-\mathrm{C}_{10} \\
\text { Rha-Rha-C}-\mathrm{C}_{8}-\mathrm{C}_{10}\end{array}$ & $\begin{array}{l}302 \\
333 \\
477 \\
480 \\
502 \\
529 \\
531 \\
531 \\
622\end{array}$ \\
\hline P. aeruginosa $\mathrm{OBP} 4$ & $\begin{array}{c}\text { Rha- } \mathrm{C}_{8: 2} \\
\text { Rha- } \mathrm{C}_{10} \\
\text { Rha- } \mathrm{C}_{12: 2} \\
\text { Rha- } \mathrm{C}_{8}-\mathrm{C}_{10} \\
\text { Rha- } \mathrm{C}_{10}-\mathrm{C}_{10} \\
\text { Rha- } \mathrm{C}_{10}-\mathrm{C}_{12} \\
\text { Rha-Rha- } \mathrm{C}_{8}-\mathrm{C}_{10} \\
\text { Rha-Rha-C } 10-\mathrm{C}_{10} \\
\text { Rha-Rha- } \mathrm{C}_{10}-\mathrm{C}_{12: 1} \\
\text { Rha-Rha- } \mathrm{C}_{10}-\mathrm{C}_{12}\end{array}$ & $\begin{array}{l}302 \\
332 \\
358 \\
477 \\
502 \\
532 \\
622 \\
648 \\
673 \\
679 \\
\end{array}$ \\
\hline
\end{tabular}

surface activity decreased due to the protonation of the rhamnolipid molecules affecting their precipitation (Xia et al. 2011).

Biosurfactants maintained their surface activity after exposure to temperatures from $4-100{ }^{\circ} \mathrm{C}$. The cell-free culture supernatants also exhibited stable surface activity even after autoclaving at $121{ }^{\circ} \mathrm{C}$ for $30 \mathrm{~min}$ (Table 2). Such thermal stability of biosurfactants indicates its utility in those industries where wet sterilization is of principal importance. The emulsification activity $\left(E_{24}\right)$ of the culture supernatant of each bacterial strain against diesel was quite stable at all the tested temperatures (Fig. 1b). Emulsions were found to be stable up to one month at LT. Emulsions were found to be stable up to one month at laboratory temperature $\left(20 \pm 1{ }^{\circ} \mathrm{C}\right)$. It is interesting to note that biosurfactants retained about $53 \%$ of their original emulsifying properties even after autoclaving, indicating their thermal stability which broadens the scope of their application in microbial enhance oil recovery (MEOR) process. The biosurfactants retained their surface activity up to the addition of $5 \% \mathrm{NaCl}$ at both normal and $\mathrm{CMD}^{-1}$ conditions (Table 3). The culture supernatants retained significant surface activity at $\mathrm{CMD}^{-2}$. Emulsification activity $\left(E_{24}\right)$ of culture supernatants against diesel remained almost unchanged upto the addition of $3 \% \mathrm{NaCl}$ (Fig. 1c). Increase in the salt concentration beyond $4 \%$, caused a significant reduction in the emulsification activity $\left(E_{24}\right)$ of culture supernatants. Such reduction in $E_{24}$ might be due to the formation of $\mathrm{Na}^{+}$-rhamnolipid complexes that reduce surface tension values. The stability of culture supernatants against higher $\mathrm{pH}$ and salinity suggests their applicability in bioremediation of marine environments and in industries where high salinities and pH prevail (Bharali et al. 2014).

\section{Chemical characterization of biosurfactants}

The TLC derived fractions showed a positive reaction to sugars with orcinol reagents and lipids with iodine vapours but possessed negative reaction to amino groups with ninhydrin. The lower 


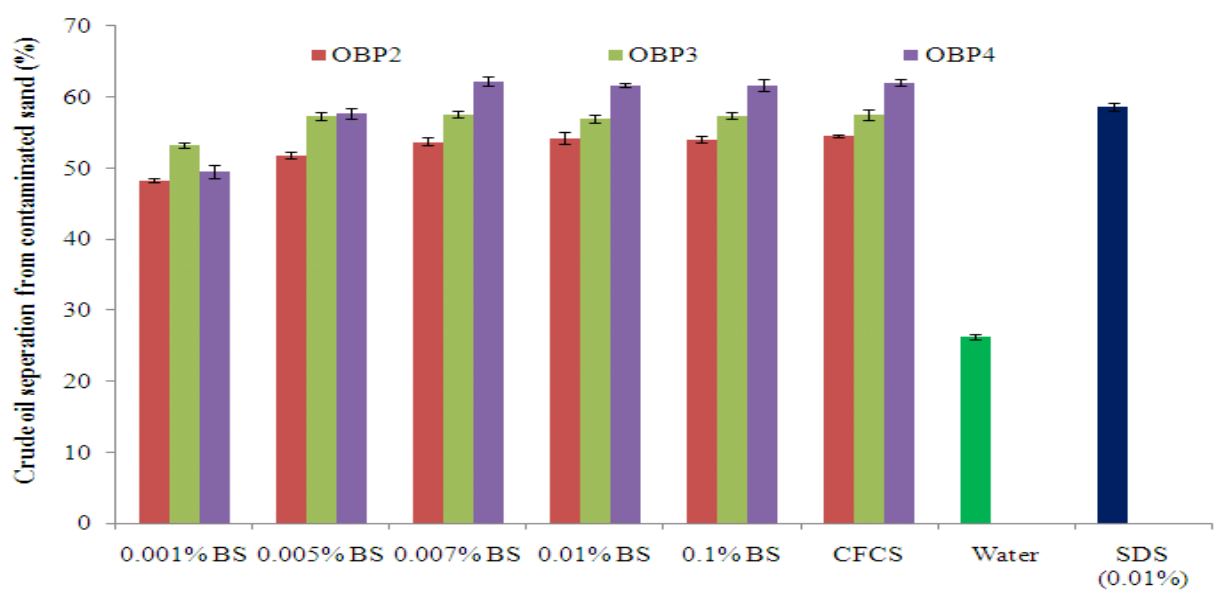

Fig. 3. Removal of crude oil from the contaminated sand after washing with biosurfactant solution (BS) produced by $P$. aeruginosa strains. CFCSCell free culture supernatant, SDS-Sodium dodecyl sulphate. Values are the mean of three independent experiments \pm standard deviation.

fractions of the average $R_{f}$ value of 0.32 while the other with an average $R_{f}$ value of 0.71 (Fig. 2). The separated fractions in TLC plates that show positive results to sugars with orcinol reagents and lipids with iodine vapors clearly indicates the presence of both glycosyl units and lipid moieties on the same spots. This confirmed the glycolipid nature of the biosurfactant produced by the bacteria. The lower fraction with the average $R_{f}$ value of 0.32 indicated the presence of di-rhamnolipids while other with an average $R_{f}$ value of 0.71 for mono-rhamnolipid molecules. These observations were found to be consistent with the reports of García-Reyeset et al. (2017).

FTIR spectrum of OBP2 biosurfactant exhibited the intense characteristic peak at $3434.00 \mathrm{~cm}^{-1}$ representing $-\mathrm{OH}$ groups. The intense stretching bands at 2927.92, 2845.91 and $1731.95 \mathrm{~cm}^{-1}$ corresponds to $\mathrm{cm}^{-1}-\mathrm{CH}_{2},-\mathrm{CH}_{3}$ and $-\mathrm{C}=\mathrm{O}$ groups, respectively. In case of OBP3 biosurfactant the peak at $3403.76 \mathrm{~cm}^{-1}$ indicates $-\mathrm{OH}$ groups. Other characteristic peaks at 2924.99, 2858.66 and $1725.97 \mathrm{~cm}^{-1}$ represents $-\mathrm{CH}_{2},-\mathrm{CH}_{3}$ and $-\mathrm{C}=\mathrm{O}$ stretching bands, respectively. The FTIR spectrum of OBP4 surfactant had an intense peak at a frequency of $3416.40 \mathrm{~cm}^{-1}$ referring to the presence of $-\mathrm{OH}$ groups. Peaks at 2929.43 and $2863.50 \mathrm{~cm}^{-1}$ represent stretching bands of $-\mathrm{CH}_{2}$ and $-\mathrm{CH}_{3}$ groups. Another characteristic peak at the frequency of $1732.60 \mathrm{~cm}^{-1}$ shows the presence of carbonyl stretching. All three spectra showed the same essential adsorption bands for the rhamnolipid type biosufactant; only the relative areas under the various absorption bands are slightly different. The appearance of additional bands in the spectra might be the result of contamination of polypeptides and polysaccharides from cell debris during the extraction of biosurfactant from the culture supernatant. The mass spectrometric analysis of the biosurfactant samples produced by $P$. aeruginosa strains shows a characteristic peak at 163, 171, 193, $205,339 \mathrm{~m} / \mathrm{z}$. The homologs structures present in the tested biosurfactant samples were identified through $\mathrm{m} / \mathrm{z}$ values (Table 4 ).

The MS investigation of the biosurfactant samples established the results of the TLC with peak values appearing at $171,193,205,339 \mathrm{~m} / \mathrm{z}$ indicated the presence of lipids and peak value at 163 for carbohydrate moiety (Aparna et al. 2012). A total of twelve rhamnolipid homologs were identified from the biosurfactants produced by the bacterial strains which included both mono and di-rhamnolipids. The results clearly showed the predominance of di-rhamnolipids over the monorhamnolipids and typically the main rhamnolipids were found to be Rha- $\mathrm{C}_{10}-\mathrm{C}_{10}$, Rha-Rha- $\mathrm{C}_{8}-\mathrm{C}_{12}$ and Rha-Rha- $\mathrm{C}_{10}-\mathrm{C}_{12}$. In the literature, the number of rhamnolipid homologues reported varies from 4 to 28 (Wittgens et al. 2017). The difference between the rhamnolipid composition and predominance of a particular type of congener in the present investigation was probably due to the factors like type of carbon substrate (Benincasa and Accorsini 2008), culture conditions, the age of the culture and the strains of $P$. aeruginos $a$ used.

\section{Possible industrial application of biosurfactant}

The aqueous biosurfactant solutions of the selected bacterial strains could efficiently separate the crude oil from the contaminated sand (Fig. 3). 
The maximum removal of crude oil by the biosurfactants was achieved up to a range of $44.2-52.0 \%$ within their CMC, but by increasing the concentration beyond the CMC the removal of crude oil from the contaminated sand could not be enhanced. Such behaviour might be due to the reduction in the interfacial tension between crude oil and the sand particles, as a result the capillary force that holds them together in the sand-oil mixture gets reduced. Such reductions in the tension further increase the contact angle between the oil and soil particles and change the wet ability of the system. This results in the mobilization of the crude oil from the sand-oil mixture to the aqueous solution.

Differences in the separation behavior of the biosurfactants samples in the washing experiment suggests that the separation process also dependent on the physico-chemical properties of the biosurfactant and combined behaviour of surfactant/crude oil/sand systems. Efficient washing off of crude oil from the contaminated sand could be achieved even with synthetic surfactant SDS. It is now well established that synthetic surfactants are more recalcitrant than the petroleum hydrocarbons and potentially toxic to the environment (Wyrwas et al. 2012; De et al. 2015). Hence, use of biosurfactant seems to be more advantageous.

The investigation of saturated sand pack column with the biosurfactant samples demonstrated their efficiency in the recovery of residual crude oil. The available residual oil in the sand pack column was mobilized during the passage of the cell-free culture broth containing biosurfactant which began to exude with the effluent. Nearly, $6.4-11.4 \%$ of the residual crude oil was recovered from the saturated sand pack column using cell-free culture supernatant of the bacterial strains as compared to the control. This is due to the fact that biosurfactants start to decrease the interfacial tension at oil/brine interface which in turn increases the capillary number of the system. Further, increase in capillary number lowers the residual oil saturation in the column and increases the recovery process (Hajibagheri et al. 2017). The recovery process from the saturated sand pack column was unaffected between $70-90^{\circ} \mathrm{C}$, which indicates the stability of biosurfactants. Such property is very crucial for their application of biosurfactants in MEOR where they have to withstand the prevailing extreme temperatures inside the oil reservoirs.

\section{Conclusions}

The selected three bacterial strains were found to be effective in producing biosurfactant in the presence of $n$-hexadecane and efficient in utilizing petroleum hydrocarbons. On the basis of biochemical and genotyping analysis the bacteria were identified as three different strains of Pseudomonas aeruginosa. Biosurfactants produced by these strains exhibited excellent surface properties and remained stable while exposed to extreme conditions of high temperature, $\mathrm{pH}$ and salinity suggesting their potential industrial applications. Chemical characterization using standard techniques confirmed the production of rhamnolipids with the predominance of di-rhamnolipids. The efficiency of isolated biosurfactants in removal and washing experiments suggests its possible applications in bioremediation. The enhanced release of crude oil at higher temperatures also confirms their thermostability that finds potential applications of crude oil recovery processes such as MEOR. The application of such hydrocarbon utilizing and biosurfactant producing indigenous bacterial strains seems advantageous for bioremediation processes in local instead of using foreign strains.

\section{Contributions of authors}

PB, SPS designed the experiments, analyzed the data. PB, YB, ND, BKK, conducted most of the experiments. SPS, CBS provided the experimental materials and performed few experiments. PB, SPS, YM, ND, BKK, CBS, DS wrote the manuscript. All authors read and approved the manuscript. The authors declare that they have no competing interests.

\section{Acknowledgement}

PB acknowledges ONGC, India for the fellowship and funding the research. The help from Chemical Sciences, Tezpur University, Tezpur, Assam, India, for various chemical analyses is gratefully acknowledged. 


\section{References}

Aparna A, Srinikethan G, Smitha H (2012) Production and Characterization of biosurfactant produced by a novel Pseudomonas sp. 2B. Colloids Surf. B Biointerfaces 95: 2-29.

Banat IM (1993) The isolation of a thermophilic biosurfactant producing Bacillus sp. Biotechnol. Lett. 15: 591-594.

Benincasa M, Accorsini FR (2008) Pseudomonas aeruginosa LBI production as an integrated process using the wastes from sunflower-oil refining as a substrate. Bioresour. Technol. 99: 3843-3849.

Bharali P, Konwar BK (2011) Production and physicochemical characterization of a biosurfactant produced by Pseudomonas aeruginosa OBP1 isolated from petroleum sludge. Appl. Biochem. Biotechnol. 164(8): 1444-1460.

Bharali P, Singh SP, Dutta N, Gogoi S, Bora LC, Debnath P, Konwar BK (2014) Biodiesel derived waste glycerol as an economic substrate for biosurfactant production using indigenous Pseudomonas aeruginosa. RSC Adv. 4: 38698-38706

Bodour AA, Maier RM (1998) Application of a modified drop collapse technique for surfactant quantification and screening of biosurfactant-producing microorganisms. J. Microbiol. Methods 32: 273-280.

Bordoloi NK, Konwar BK (2007) Microbial surfactantenhanced mineral oil recovery under laboratory conditions. Colloids Surf. B Biointerfaces 63: 73-82.

Chandrasekaran EV, BeMiller JN (1980) Constituents analysis of glycosaminoglycans. In Whistler RL (Ed.), Methods in carbohydrate chemistry, Academic Press, New York, USA, 349 p.

Chen J, Wu Q, Hua Y, Chen J, Zhang H, Wang H (2017) Potential applications of biosurfactant rhamnolipids in agriculture and biomedicine. Appl. Microbiol. Biotechnol. 101: 8309-8319.

De S, Malik S, Ghosh A, Saha R, Saha B (2015) A review on natural surfactants. RSC Adv. 5: 65757-65767.

García-Reyes S, Yáñez-Ocampo G, Wong-Villarreal A, Rajaretinam RK, Thavasimuthu C, Patiño R, OrtizHernández ML (2017) Partial characterization of a biosurfactant extracted from Pseudomonas sp. B0406 that enhances the solubility of pesticides. Environ. Technol. 22: 1-10.

Haba E, Pinazo A, Jauregui O, Espuny MJ, Infante MR, Manresa A (2003) Physicochemical characterization and antimicrobial properties of rhamnolipids produced by Pseudomonas aeruginosa 47T2 NCBIM 40044. Biotechnol. Bioeng. 81: 316-322.

Hajibagheri F, Lashkarbolooki M, Ayatollahi S, Hashemi A (2017) The synergic effects of anionic and cationic chemical surfactants, and bacterial solution on wettability alteration of carbonate rock: An experimental investigation. Colloids Surf. A 513: 422-429.

Irorere VU, Tripathi L, Marchant R, McClean S, Banat IM (2017) Microbial rhamnolipid production: a critical reevaluation of published data and suggested future publication criteria. Appl. Microbiol. Biotechnol. 101: 3941-3951.

Johnson M, Boese-Marrazzo D (1980) Production and properties of heat stable extracellular hemolysin from Pseudomonas aeruginosa. Infect. Immun. 29: 10281033.

Kumar G, Kumar R, Sharma, A (2015) Characterization of biosurfactants from indigenous soil bacteria recovered from oil contaminated sites. J. Environ. Bio. 36: 1101-1104.

Kumar S, Tamura K, Nei M (1994) MEGA: molecular evolutionary genetics analysis software for microcomputers. Comput. Appl. Biosci. 10: 189-191.

Kuppusamy S, Thavamani P, Venkateswarlu K, Lee YB, Naidu R, Megharaj M (2017) Remediation approaches for polycyclic aromatic hydrocarbons (PAHs) contaminated soils: Technological constraints, emerging trends and future directions. Chemosphere 168: 944968.

Mulligan CN, Gibbs BF (2004) Types, production and applications of biosurfactants. Proc. Nat. Sci. Acad. 70: 31-55.

Parthipan P, Elumalai P, Sathishkumar K, Sabarinathan D, Murugan K, Benelli G, Rajasekar A (2017) Biosurfactant and enzyme mediated crude oil degradation by Pseudomonas stutzeri NA3 and Acinetobacter baumannii MN3. 3 Biotech 7: 278.

Pristas P, Stramova Z, Kvasnova S, Judova J, Perhacova Z, Vidova B, Sramkova Z, Godany A (2015) Non-ferrous metal industry waste disposal sites as a source of polyextremotolerant bacteria. Nova Biotechnol. Chim. 14: 62-68.

Radzuan MN, Banat IM, Winterburn J (2017) Production and characterization of rhamnolipid using palm oil agricultural refinery waste. Bioresour. Technol. 225: 99105.

Rahman MF, Rusnam M, Gusmanizar N, Masdor NA, Lee CH, Shukor MS, Roslan MAH, Shukor MY (2016) Molybdate-reducing and SDS-degrading Enterobacter sp. Strain Neni-13. Nova Biotechnol. Chim. 15: 166181.

Saikia RR, Deka S, Deka M, Banat IM (2012) Isolation of biosurfactant-producing Pseudomonas aeruginosa RS29 from oil-contaminated soil and evaluation of different nitrogen sources in biosurfactant production. Ann. Microbiol. 62: 753-763.

Siegmund I, Wagner F (1991) New method for detecting rhamnolipids excreted by Pseudomonas species during growth on mineral agar. Biotechnol. Technol. 5: 265268.

Silva MA, Silva AF, Rufino RD, Luna JM, Santos VA, Sarubbo LA (2017) Production of biosurfactants by Pseudomonas species for application in the petroleum industry. Water Environ. Res. 89: 117-126.

Suthar H, Hingurao K, Desai A, Nerurkar A (2008) Evaluation of bioemulsifier mediated microbial enhanced oil recovery using sand pack column. J. Microbiol. Methods 75: 225-230. 
Wittgens A, Kovacic F, Müller MM, Gerlitzki M, SantiagoSchübel B, Hofmann D, Tiso T, Blank LM, Henkel M, Hausmann R, Syldatk C, Wilhelm S, Rosenau F (2017) Novel insights into biosynthesis and uptake of rhamnolipids and their precursors. Appl. Microbiol. Biotechnol. 101: 2865-2878.

Wyrwas B, Chrzanowski Ł, Ławniczak Ł, Szulc A, Cyplik P, Białas W, Szymański A, Hołderna-Odachowska A (2012) Utilization of Triton X-100 and polyethylene glycols during surfactant-mediated biodegradation of diesel fuel. J. Hazard. Mater. 197: 97-103.

Xia WJ, Dong HP, Yu L, Yu DF (2011) Comparative study of biosurfactant produced by microorganisms isolated from formation water of petroleum reservoir. Colloids Surf. A Biointerfaces 392: 124-130.

Yonebayashi H, Yoshida S, Ono K, Enomoto H (2000) Screening of microorganisms for microbial enhanced oil recovery process. Sekiyu Gakkaishi 43: 59-69.

Zhang Y, Zhao Q, Jiang J, Wang K, Wei L, Ding J, Yu H (2017) Acceleration of organic removal and electricity generation from dewatered oily sludge in a bioelectrochemical system by rhamnolipid addition. Bioresour. Technol. 243: 820-827.

Zaman AU (2010) Comparative study of municipal solid waste treatment technologies using life cycle assessment method. Int. J. Environ. Sci. 7: 225-235. 